\title{
As contradições entre as medidas antiterroristas e os direitos humanos no contexto dos Estados Democráticos de Direito
}

\section{The contradictions between anti-terrorism measures and the human rights in the context of the democratic States of Law}

\author{
Anna Claudia Lavoratti* \\ Cleide Lavoratti ${ }^{* \star}$
}

\begin{abstract}
Resumo: A globalização, conjuntamente com as benesses dos avanços tecnológicos, trouxe consigo novos riscos que integram a denominada sociedade de risco. É nesse âmbito que se insere o terrorismo no formato contemporâneo, e o generalizado sentimento de insegurança por este proporcionado, em especial, após o ataque ocorrido nos Estados Unidos no dia 11 de setembro de 2001. Como resposta a esse fenômeno, os Estados têm instituído medidas que colocam em risco os direitos humanos. Assim, por meio de uma pesquisa de natureza qualitativa, utilizando-se do método dialético, do levantamento bibliográfico e documental, foi realizada a análise das influências sobre o conteúdo e a forma com que essas medidas são introduzidas nos ordenamentos jurídicos, de uma maneira geral, o que possibilitou a verificação de em que medida essas são compatíveis com a atual formatação de Estado Democrático de Direito, produto de um novo constitucionalismo, e com a própria concepção dos direitos humanos.
\end{abstract}

Palavras-chave: Sociedade de Risco. Medidas antiterroristas. Estado Democrático e Constitucional de Direito.

\begin{abstract}
Globalization, along with the benefits of technological advances, has brought with its new risks that are part of the so-called risk society. It is within this framework that terrorism forms in the contemporary format is inserted together with the generalized sense of insecurity or state of tension caused by it, especially after the attack in the United States on September 11, 2001. In
\end{abstract}

\footnotetext{
* Mestre em Ciências Jurídico-Políticas com menção em Direito Constitucional pela Universidade de Coimbra - Portugal. Advogada formada pelo Centro Universitário Assis Gurgacz. Professora de Direito Constitucional, Direitos Humanos e Direito Agrário. Servidora Pública Federal no Instituto Nacional do Seguro Social. E-mail: aclavoratti@outlook.com.

** Doutora e mestre em Sociologia pela Universidade Federal do Paraná. Assistente Social pela Universidade Estadual de Ponta Grossa. Docente do Departamento de Serviço Social da Universidade Estadual de Ponta Grossa. E-mail: lavoratti@ yahoo.com.br
} 
response to this phenomenon, States have instituted measures that endanger human rights. Therefore, through a qualitative research, using the dialectic method, bibliographic and documentary survey, it has been carried out an analysis of the influences on the content and the way in which these measures are introduced in the legal systems, in general, which enabled the verification of the extent to which these are compatible with the current format of the Democratic State of Law, the product of a new constitutionalism, and with the very conception of human rights.

Key-words: Society of risk. Counter-terrorism measures. Democratic and Constitutional State of Law.

Recebido em: 02/04/2020. Aceito em: 22/10/2020.

\section{Introdução}

Não obstante no âmbito filosófico e jurídico contraponham-se diversas teorias acerca da natureza dos direitos do homem, seja como direitos naturais ${ }^{1}$ ou, ainda, como produto histórico e dependente de positivação ${ }^{2}$, certo é que o indivíduo é titular legítimo de direitos humanos ${ }^{3}$ que devem ser resguardados pelo Estado e, apenas como ultima ratio, restringidos ou suprimidos.

Diante da consideração de tais direitos, derivam-se obrigações positivas e negativas impostas ao Estado que, compreendido a partir de uma perspectiva contratualista, possui o monopólio do uso da força legitimado, tendo este a contraprestação de garantir esses mesmos direitos, seja promovendo medidas para protegê-los frente a terceiros ou se abstendo de violá-los.

Todavia, a postura do Estado em garantir direitos humanos é abalada frente a nova realidade moldada a partir do século XX, este compreendido como indústria responsável pela produção de fenômenos de natureza díspares.

Tal assertiva se afirma ao considerar que, simultaneamente em resposta ao pós-guerra e aos totalitarismos vivenciados, bem como às posteriores ditaduras, emergiu a necessidade de uma nova sistemática protetiva ampla que assegurasse os direitos humanos frente ao próprio arbítrio estatal. Por outro lado, as tensões oriundas desse século inerentes a mudanças com reflexos globais, como a criação de um estado judaico, somadas ao desenvolvimento das novas tecnologias, trouxeram novos riscos ${ }^{4}$ para a sociedade civil organizada, cujo combate colocou em risco diversas vertentes de direitos.

\footnotetext{
${ }^{1}$ Conforme a tradição filosófica contratualista, os direitos naturais são os direitos inerentes ao indivíduo e anteriores a qualquer contrato social. (HAARSCHER, 2003, p. 394).

${ }^{2}$ Remete-se à Escola do Positivismo Exegético.

${ }^{3}$ Salienta-se, de início, que foi construída uma diferença terminológica ao tratar de direitos sob uma dimensão jusnaturalista universalista, os denominados direitos humanos ou direitos dos homens, que se referem aqueles válidos para todos os povos em todos os tempos, e em um segundo momento os direitos fundamentais condizentes aqueles objectivamente vigentes em uma ordem jurídica concreta. (CANOTILHO, 2003, p. 393). No presente trabalho será adotado o termo direitos humanos como uma forma de abranger os direitos sob uma perspectiva universal.
}

${ }^{4}$ Para um apanhado maior sobre os novos riscos oriundos da globalização sob o viés do direito penal, ver: Ver FERNANDES, 
Dentre esses novos desafios se encontra o terrorismo no formato contemporâneo, caracterizado pelos instrumentos de atuação possibilitados pela globalização e seus avanços tecnológicos, tais quais as armas biológicas, bombas etc.

Destaca-se que a grande dimensão alcançada pelo terrorismo nas últimas décadas, responsável por este adquirir maior pauta nas discussões a nível global, se deu especialmente a partir do atentado ocorrido em 11 de Setembro de 2001 nos Estados Unidos, o qual despertou um sentimento de insegurança e descrédito em relação à tutela conferida pelo poder estatal.

Como resposta a este evento e a crescente ocorrência de atentados após o ano de 2001, verificou-se por parte dos Estados uma postura ativa no sentido de implementar medidas administrativas e jurídicas antiterroristas mais rígidas, sejam elas repressivas e até mesmo preventivas.

Emerge, nessa seara, a questão de analisar se o desespero dos Estados em combater esse fenômeno não tem o condão de resultar em medidas de austeridade que, não apenas colidam com direitos humanos, mas muitas vezes os suspendam e até revoguem sem a utilização de critérios adequados, como a proporcionalidade e, além disso, confrontem os próprios princípios que fundamentam soberania e legitimidade do ente estatal.

Para que seja possível compreender a problemática existente acerca da legitimidade e compatibilidade das medidas antiterroristas introduzidas em um contexto democrático, é necessário através do método dialético, da pesquisa bibliográfica e documental, verificar inicialmente, a partir da evolução do constitucionalismo, a fundamentação histórica afirmativa dos direitos humanos, principalmente como forma de defesa contra o Estado. Ademais, se mostra indispensável a análise da formatação do terrorismo contemporâneo, tendo em vista que este, em virtude de sua potencialidade, exige, como consequência a adoção de medidas combativas pelas autoridades governamentais que afetam os direitos humanos.

Nesse entremeio, considerando o ataque de 11 de Setembro de 2001 como divisor de águas quanto ao tratamento jurídico do terrorismo, colocar-se-á sob enfoque alguns exemplos de legislações antiterroristas implementadas após esse evento, em especial, a francesa e inglesa, visto que tais países, sob um viés preventivo em relação à eventuais e futuros ataques terroristas, promoveram uma intensiva produção legislativa nesse campo. Por meio dessa seleção realizar-se-á o exame das cargas valorativas que essas leis carregam para, por fim, verificar se as medidas introduzidas são compatíveis com o Estado Constitucional e Democrático de Direito.

\section{A evolução da tutela dos direitos humanos sob a perspectiva do constitucionalismo e o despertar protetor do direito internacional no século XX}

Ao partir da premissa que foram os diversos movimentos constitucionais os responsáveis por proporcionar a concepção hodierna de Estado Constitucional Democrático de Direito, erigido sob uma Constituição com força normativa na qual encontram-se positivados os direitos humanos, assumindo nesta, o caráter de direitos fundamentais, é necessária a análise histórica no fito de compreender tais direitos não como concessões do Estado, mas como aqueles que, além de inerentes ao ser humano sob uma perspectiva de direito natural, também tiveram sua garantia e afirmação historicamente conquistada.

Paulo Silva. Globalização, “Sociedade de Risco” e o Futuro do Direito Penal. Coimbra: Almedina, 2001, p. 61. 


\section{O Constitucionalismo Antigo e Moderno}

O termo constitucionalismo, não obstante de aparência recente no seio histórico-jurídico é apontado pela doutrina como tendo seus ideais de limitação do poder e supremacia da lei traçados no período antigo, especialmente nas cidades de Atenas e Roma.

Segundo Luís Roberto Barroso (2013), com a implantação da República em Roma (529 a.C.) passou a ser compartilhado a ideia de limitação do poder. A cidade de Atenas também é considerada um berço dos ideais constitucionalistas, uma vez que concebeu ideais e institutos ainda existentes atualmente, tais quais: a divisão de funções do estado em diversos órgãos, a previsão de um sistema judicial e, principalmente a ideia de uma lei criada por um processo forma adequado e válida para todos.

Ademais, o pensamento socrático já abria uma perspectiva de combater a autoridade ao exigir justificações racionais para a pretensão do exercício do poder. Assim, afirma Guy Haarscher (1997) que foram Sócrates e Platão os responsáveis por introduzir o racionalismo na política, na medida em que a autoridade passou a ser submetida a um processo de justificação argumentada.

Apesar do período antigo não ser referência quanto à previsão do modelo de Constituição atual, nele já se fazia menção a uma ideia desse documento. Nesse sentido, Aristóteles (2000, p. 206) trouxe inclusive uma definição: “[...] por constituição entendo a organização das várias autoridades, e em particular da autoridade suprema, que está acima de todas as outras. Mas [...] o corpo dos cidadãos é soberano; a constituição é a soma total da politeuma".

Quanto à idade das trevas, esta não é considerada como indicador histórico no que tange ao desenvolvimento europeu dos propósitos constitucionalistas acima mencionados, considerando que a Idade Média, especialmente em sua decadência, erigiu as bases do desenvolvimento de um Estado Absolutista que desconhecia a limitação de poder e, no qual, a lei confundia-se com a vontade do soberano, apoiada pela Igreja Católica para sua ascensão.

Entretanto, importa destacar que esta instituição religiosa protagonizou importante papel no período medievo no que tange ao desenvolvimento dos direitos humanos, ao realizar, consoante Ugatti (2008, p. 49-51), a “[...] consagração do ideário de que cada pessoa humana tem um valor absoluto no plano espiritual" e ao atribuir o elemento teleológico ao direito, embora a titularidade dos direitos variasse conforme o papel que cada cidadão ocupava segundo a estratificada sociedade feudal.

Já o jusnaturalismo racionalista, produto da modernidade, não admitia a citada "estratificação social com base no privilégio do nascimento" (UGATTI, 2008, p. 56) vislumbrada no sistema feudal. Pelo contrário, pregavam a construção de uma sociedade com cidadãos sujeito de direitos, e não como meros súditos, que interagiam por relações horizontais em razão dessa comunidade ser produto do contrato social.

Ainda que os termos supremacia da lei e limitação do poder não fossem utilizados expressamente, esses podem ser visualizados nas justificações de algumas teorias contratualistas que buscaram explicar a legitimação do surgimento do Estado, visto que, de uma forma geral, essas fazem alusão à existência de um estado natural onde os indivíduos gozam de plena liberdade e, na busca de uma maior realização dos seus direitos naturais, esses indivíduos abrem mão de parcela dessa liberdade para que, na sociedade política, a autoridade nela implicada promova uma maior realização e garantia desses direitos ${ }^{5}$.

\footnotetext{
${ }^{5}$ Salienta-se as teorias contratualistas foram variadas e nem sempre seguiam essa lógica, nesse sentido, Thomas Hobbes justificava o Absolutismo na sua teoria descrita no "O Leviatã” (HAARSCHER, 1997).
} 
Por conseguinte, mesmo que pelo pacto à autoridade (Estado) seja atribuído o monopólio legítimo da força, esse é limitado pela garantia de certos direitos (HAARCHER, 1997).

Salienta-se que a forma como o Estado administra esse monopólio da força tem sido objeto de questionamentos ao longo da história, especialmente na Idade Moderna, onde se vislumbrou o progresso dos ideais constitucionalistas supracitados, visto que neste período foram visualizados conflitos de cunho contestatório aos diversos absolutismos presentes, difundindo ideais de limitação do poder e da supremacia da lei.

Dentre os diversos movimentos constitucionalistas experienciados, cita-se a Inglaterra do século XVII onde os diversos conflitos políticos oriundos da oposição entre Monarquia absolutista e o Parlamento, resultaram na aprovação do Bill of Rights, gatilho da introdução do formato de um Estado de Direito fundado na separação de poderes, uma vez que tal documento consagrou a Supremacia Parlamentar como forma de proteção do indivíduo contra o arbítrio estatal (MONDAINI, 2006).

Alude-se aos Estados Unidos da América do século XVIII como outro movimento constitucional que, após a Revolução Americana resultar na independência do país em 4 de julho de 1776, conquistou em 17 de setembro de 1787 a aprovação do texto constitucional que simbolizou a primeira constituição escrita no mundo moderno, caracterizada por implantar um governo constitucional erigido sobre os primados de igualdade, supremacia da lei e separação de poderes. (BARROSO, 2013).

Como último referente a ser abordado, a França do século XVIII vivia uma grave crise financeira em um contexto de desenvolvimento da classe burguesa nascida da Revolução Industrial. Desse modo, como a nobreza se negou a reduzir seus privilégios, foram convocados os Estados Gerais (integrada pela nobreza, clero e terceiro estado) e o terceiro estado autoproclamou-se Assembleia Nacional e em seguida Assembleia Constituinte (BARROSO, 2013).

O contexto da Revolução Francesa, durante a qual o Ancién Regime fora combatido, permitiu o desenvolvimento dos direitos de primeira dimensão concernentes às liberdades individuais que, segundo Haarscher (1997), eram protegidos sob um aspecto individualista, na medida em que objetivavam tutelar os interesses apenas da alta burguesia contra o Estado e na lógica do desenvolvimento da doutrina liberal.

Inobstante este individualismo ${ }^{6}$, não se pode deixar de notar que resultaram em mudanças substanciais com efeitos irradiadores, posto a consolidação de valores como o sufrágio universal, a soberania popular, separação de poderes (BARROSO, 2013). Ademais, foi nessa conjuntura que foi compilada a Declaração Universal dos Direitos do Homem e do Cidadão de 1789, responsável pela tradição universalista de reconhecimento dos direitos civis e que teve os seus ideais revolucionários migrados para além dos limites das fronteiras nacionais (MONDAINI, 2006).

Tal declaração emergiu como uma resposta necessária à proteção dos direitos do homem diante de uma sociedade que, até então, era flagelada pelos privilégios concedidos a certas camadas sociais em detrimento de outras. Dessa via, segundo Hannah Arendt (2012, p. 324), esse documento introduziu o significado que "[...] doravante o Homem, e não o comando de Deus nem os costumes da história, seria a fonte da Lei".

\footnotetext{
${ }^{6}$ Nesse sentido, Eric J. Hobsbawm (apud UGATTI, 2008, p. 61) afirma que a Declaração dos direitos do homem e do cidadão "era um manifesto contra a sociedade hierárquica de privilégios nobres, mas não um manifesto a favor de uma sociedade democrática e igualitária”.
} 
Feita as considerações acerca dos movimentos constitucionalistas no período moderno, pode-se afirmar que esse foi caracterizado pela consolidação da concepção de um Estado de Direito ancorado no Princípio da Legalidade, bem como pelas declarações de direitos e constituições modernas que proclamaram direitos a todos os indivíduos, todavia, quanto às declarações de direitos, a sua eficácia apenas se visualizava nos Estados signatários das mesmas?

\section{Constitucionalismo Contemporâneo ou Neoconstitucionalismo}

No século XX, com a eclosão das duas grandes guerras, a garantia dos direitos humanos encontrou obstáculos quanto à sua concretização. Nesse quadro, afirma Mondaini (2006) que os direitos humanos contaram com um emaranhado extremamente heterogêneo de rivais gerados pela polarização entre capitalismo e comunismo e, como produto dessa disputa, o surgimento das formas mais variadas de fanatismo político-ideológico, os quais podem ser perfeitamente visualizados no nazismo e stalinismo, entre outros regimes ditatoriais, de esquerda ou direita.

Diante das arbitrariedades e latentes violações às mais diversas categorias de direitos humanos que foram presenciadas na instalação dos regimes totalitários e no decorrer da Segunda Guerra Mundial, bem como em razão dos violadores se consolidaram nas figuras dos próprios Estados, cujas ações foram legitimadas por estarem sob proteção da lei, restou evidente que o modelo de Estado de Direito (the rule of law) introduzido pelo constitucionalismo moderno, no qual atribuía-se como limite ao arbítrio estatal a mera subsunção de suas medidas ao crivo da legalidade, demonstrou-se insuficiente por não oferecer uma tutela efetiva aos direitos humanos.

Foi essa conjuntura histórica e política que permitiu o desenvolvimento do movimento neoconstitucionalista ${ }^{8}$, caracterizado por uma nova acepção de Estado sob uma linha pós-positivista, o qual, sem abandonar a legalidade como fundamento, buscou, consoante Barroso (2013, p. 288), “[...] empreender uma leitura moral do direito, mas sem recorrer a categorias metafísicas”.

Outrossim, no plano nacional foram reconhecidas as Constituições Normativas ${ }^{9}$ que no seu bojo, além de limitar o poder estatal, introduziram uma gama de direitos humanos nomeadamente direitos fundamentais, dos quais se originam obrigações positivas e negativas no fito de melhor promover a sua proteção.

Além disso, da recusa aos totalitarismos, a nova concepção de Estado, de um Estado Constitucional, derivou da soma de duas categorias: Estado de Direito e Estado Democrático, visto que além da limitação do poder em uma Constituição ou documento jurídico face o princípio da legalidade ${ }^{10}$, a ordem de domínio deveria ser legitimada pelo povo (CANOTILHO, 2003).

Desse modo, é possível conceber o Estado Democrático como produto de uma vontade popular que legitima o seu poder e, em contrapartida, recai a incumbência da proteção de direitos humanos, sendo estes fundamentos do pacto e não concessões estatais.

\footnotetext{
${ }^{7}$ Dessa via, segundo Mário Reis Marques (2014, p. 2.006) “[...] de fora do seu perímetro de eficácia ficam as mulheres, os operários, os negros e os judeus".

${ }^{8} \mathrm{O}$ termo neoconstitucionalismo identifica o constitucionalismo democrático pós-guerra, marcado pela força normativa da constituição, pela expansão da jurisdição constitucional e por uma nova hermenêutica (interpretação).

${ }^{9}$ A Constituição Normativa, segundo Canotilho (2003), é uma constituição estruturante de uma ordem jurídico-normativo fundamental vinculativa de todos os poderes públicos. Trata-se de uma verdadeira ordenação normativa fundamental dotada de supremacia (supremacia da Constituição).

${ }^{10}$ Ressalta-se que o Princípio da Legalidade sofreu certa relativização em prol ao Princípio da Constitucionalidade que, de acordo com SILVA (2003, p. 122), é entendido como expressão “em primeiro lugar, que o Estado Democrático de Direito se funda na legitimidade de uma constituição rígida, emanada da vontade popular, que, dotada de supremacia, vincule todos os poderes e os atos deles provenientes, com as garantias de atuação livre de regras da jurisdição constitucional".
} 


\section{A emergência de proteção dos direitos humanos no âmbito internacional}

$\mathrm{Na}$ mesma exegese que sustentou a construção de um novo Estado Constitucional Democrático, os reflexos da segunda guerra mundial também atingiram o direito internacional, considerando que emergiu a necessidade deste coprotagonizar com os Estados Nacionais a tutela dos direitos humanos ${ }^{11}$.

Buscando estabelecer mecanismos internacionais intervencionistas com pretensões universalistas, foi criada em 26 de junho de 1945 a Organização das Nações Unidas - ONU (UGATTI, 2008). Em seguida, a Assembleia Geral das Nações Unidas se mobilizou para proclamar os direitos fundamentais da humanidade e o respeito inviolável à dignidade da pessoa humana por meio da aprovação da Declaração Universal dos Direitos do Homem em 10 de dezembro de 1948 (MONDAINI, 2006).

Tal documento, diferente das declarações de direitos oriundas dos movimentos americano e francês, restou libertado do quadro nacional e passou a ter a sua aplicação promovida por instâncias superiores aos próprios Estados. Por tal razão, entende-se que é nesse momento em que de fato os direitos humanos passam a ter verdadeira positivação jurídica e são reconhecidos como válidos universalmente (MARQUES, 2014).

Importa destacar que a preocupação acerca da tutela desses direitos retomou grande visibilidade no século passado com a febre de ditaduras vislumbradas especialmente a partir da década de 60. Isso porque, com o fim desses regimes de caráter autoritário que promoveram graves violações a direitos fundamentais, em especial às diversas vertentes da liberdade, as últimas duas décadas do século XX caracterizaram-se por um fortalecimento dos regimes democráticos e a promulgação de Constituições amplamente garantistas quanto à proteção de direitos, bem como no desenvolvimento da proteção internacional dos mesmos ${ }^{12}$.

A partir desse novo aparato é que se passou a propor a ideia de um constitucionalismo global, caracterizado pela associação entre o jus cogens ${ }^{13}$ internacional plasmado em declarações e documentos universais, e a tutela de direitos humanos pela tendencial elevação da dignidade humana como pressuposto ineliminável de todo constitucionalismo (CANOTILHO, 2003).

Não obstante ainda não se possa afirmar a ocorrência de um verdadeiro constitucionalismo global, nos moldes de servir o jus cogens internacional como parâmetro de validade das constituições internas, bem como na certeza do estabelecimento de um standard humanitário com força vinculante, não se pode deixar de notar que alguns instrumentos internacionais de direitos humanos exercem força conformadora, de modo a estabelecer um conjunto de padrões materiais mínimos impostos aos Estados quanto a certas obrigações jurídicas acerca de um sistema penal e processual justo, a proteção de direitos básicos e garantias de cidadania (CANOTILHO, 2003).

\footnotetext{
${ }^{11}$ Nessa exegese, conforme Jürgen Habermas (apud MARQUES, 2014, p. 2.009), foi “[...] justamente a catástrofe criada por este conflito que gerou uma reacção global e potenciou um novo lenitivo para o desenvolvimento dos direitos humanos".

${ }^{12}$ Cita-se como exemplo a Constituição Brasileira que como "resposta" a ditadura brasileira, trouxe em seu corpo uma ampla previsão acerca de direitos fundamentais no artigo 5, destacando a garantia das liberdades individuais.

${ }^{13}$ Conforme Francisco de Vitória (apud ACCIOLY, Hildebrando; SILVA, G. E. do Nascimento e; CASELLA, Paulo Borba), tratase o jus cogens do "direito das gentes", o qual "[...] não tem somente força de pacto ou de convenção entre os homens, mas possui, igualmente, força de lei. O mundo inteiro, na verdade, que, de certo modo, constitui uma república, tem o poder de levar leis justas e ordenadas para o bem de todos, tais como são as do direito das gentes. Consequentemente, quando se trata de questões graves, nenhum estado pode se considerar desvinculado do direito das gentes, pois este é colocado pela autoridade do mundo inteiro".
} 


\section{O novo estado proporcionado pelo terrorismo internacional na virada do século XX (reação pós 11 de Setembro de 2001) e a conflitividade entre direitos}

Embora o século anterior tenha fornecido pilares para a construção de vertente evolutiva de tutela dos direitos humanos como resposta às graves violações dos mesmos nesse limiar histórico, o fenômeno do terrorismo é um dos principais responsáveis por colocar em risco a construção de um paradigma de proteção efetiva.

Ao tratar da terminologia "terrorismo", preliminarmente importa mencionar que esse não é produto do último século como comumente se presume. O termo é considerado bastante antigo se notarmos que já era usado pelos Jacobinos para se auto designar durante a Revolução Francesa (GEARSON , 2002) ${ }^{14}$.

Ademais, também foi possível a visualização da ocorrência de vários ataques terroristas de natureza internacional no século $\mathrm{XX}^{15}$. Entretanto, o terrorismo até então conhecido era aquele com âmbito de atuação específica, realizado por grupos delimitados, cujos integrantes vinham de círculos sociais concretos e que agiam segundo determinados padrões de conduta, possibilitando, assim, certa previsão de suas ações pelos Estados (DURÁN, 2010).

Ocorre que a sociedade pós-industrial, ou ainda, denominada por Ulrich Beck como sociedade de risco, considerada como resultado de decisões humanas que põe em perigo a própria sobrevivência do homem em razão da "evolução a todo custo" (FERNANDES, 2001, p. 19), forneceu subsídios tecnológicos para o terrorismo no formato global.

Ressalta-se que essa nova concepção de terrorismo internacional e a dimensão que esse passou a ocupar na agenda mundial tem como referência o ataque de 11 de Setembro de 2001. (MASFERRER , 2011). Ademais, o novo terrorismo excede os antigos formatos de conflito armado entre indivíduos em dado espaço físico, pois possui caráter transfronteiriço e, sobretudo, ao alocar a sociedade como alvo de ataques de armas biológicas, químicas ou das bombas-relógio (produtos de uma sociedade de risco), ainda que esse não seja o objetivo principal, provoca constante tensão relativa à existência ou não de expectativa quanto aos Estados serem capazes de promover a segurança face as ameaças terroristas ${ }^{16}$.

Frente essa nova realidade difundida de modo enfático a partir do ano de 2001, na qual um ataque terrorista poderia ocorrer a qualquer momento e em qualquer lugar do globo difundindo uma sensação de perigo difuso, passa a sociedade a se situar em um novo estado que, de acordo com Durán (2010), encontra-se entre o estado de normalidade - no qual os conflitos são resolvidos pelas normas ordinárias - e o estado de exceção - que corresponde às crises extraordinárias -, qual seja esse: o estado de tensão em que, segundo o autor "[...] a normalidade é submetida a um estado de perigo com intensidade extraordinária, que além de podem ocorrer em qualquer momento, o risco de se concretizar trazem graves consequências as pessoas e uma sensação generalizada de insegurança, todavia, não justificam a declaração de um Estado de Exceção" [tradução nossa]. (DURÁN, 2010, p. 22).

\footnotetext{
${ }^{14}$ No mesmo sentido, afirma Muñoz (2011), que é na Revolução Francesa, especialmente no período do "terror" que o terrorismo aparece como violência organizada.

${ }^{15}$ Cita-se como referência o Setembro Negro ocorrido em 05/09/1972 nos Jogos Olímpicos de Munique no qual um grupo palestino entrou nas instalações e raptou os atletas israelitas para assassiná-los.

${ }^{16}$ Essa tensão revela-se pelo sentimento generalizado de insegurança próprio da sociedade de risco, o qual é potencializado pelos meios de comunicação, pelos quais o distante e o próximo dos acontecimentos tem uma presença quase idêntica na recepção do acontecimento danoso decorrente desses novos riscos. (FERNANDES, 2001, p. 21).
} 
Em busca de soluções contra as práticas terroristas pelos Estados, emerge uma zona jurídica de nebulosa conflitividade acerca da garantia de direitos humanos que, embora não sejam absolutos nem ilimitados, na contraposição entre garantia da segurança nacional e os direitos individuais, pode-se inferir uma certa tendência pela prevalência da proteção do primeiro em detrimento dos demais direitos, tais quais a liberdade, intimidade e, em particular, integridade física intimamente ligada à dignidade humana. Nessa linha, Urbano (2016, p. 38) destaca que: "[...] num mundo de medo, há uma tendência crescente para perseguir a segurança à custa dos direitos fundamentais”.

É nesse sentido que afirma Royo (2010) que o combate ao fenômeno terrorista é considerado por certos países e doutrinas jurídicas não apenas como uma emergência estatal, mas uma guerra da qual não deve haver outro resultado se não a vitória.

Vale salientar que as próprias Constituições de raízes neoconstitucionalistas trouxeram junto ao grande catálogo de direitos fundamentais, a previsão do estado de exceção, durante os quais, por exemplo, certos direitos podem ser objeto de suspensão temporária.

Também no âmbito internacional, a Convenção Europeia de Direitos do Homem (CEDH) permite no artigo $15^{\circ}$ que, estando um Estado em guerra ou diante de outro perigo público “[...] que ameace a vida da nação", pode este promover a revogação de obrigações previstas na Carta, limitado a disposição constante no ponto 2 do artigo que não permite a derrogação do artigo $2^{\circ}$, salvo quanto ao caso de morte resultante de atos ilícitos de guerra, nem aos artigos $3^{\circ}, 4^{\circ}$ (parágrafo 1) e $7^{\circ}$ ".

Acresce ao exposto a previsão da Convenção Americana de Direitos Humanos (Pacto de São José da Costa Rica) no art. 27, onde consta que nas hipóteses de guerra, perigo público, ou de outra emergência que ameace a independência ou segurança do Estado Parte "este poderá adotar disposições que, na medida e pelo tempo estritamente limitados às exigências da situação, suspendam as obrigações contraídas em virtude desta Convenção".

Embora seja necessário o atendimento de certos requisitos e pressupostos fáticos para a invocação dos regimes emergenciais, questiona-se se esses figuram como melhores soluções no combate a essa modalidade de emergência.

Além disso, ante as medidas antiterroristas nem sempre serem introduzidas no contexto do estado de exceção formalmente declarado, mas através da legislação ordinária, dúvidas emergem acerca dos limites das mesmas, isto é, até que ponto relativizam direitos humanos sob critérios legais e em que medida o limiar acaba sendo cruzado em prol a uma verdadeira revogação de direitos humanos?

Desse modo, a análise atinente às medidas antiterroristas não se situa em questionar se essas devem ou não ser instituídas, pois não há dúvidas que o fenômeno terrorista deve ser reprimido. A grande problemática emerge da forma e dimensões como são introduzidas no ordenamento jurídico e quanto à sua compatibilidade com o Estado Democrático de Direito.

\section{Tratamento dos direitos humanos no combate ao terrorismo internacional}

\section{A influência da doutrina do Direito Penal do Inimigo}

O cenário proporcionado pelo risco de terrorismo é responsável por colocar em choque uma gama de direitos humanos. Em um primeiro momento se objetiva proteger o direito à segurança de uma coletividade, cuja tutela remonta as concepções justificadoras do contratualismo e 
o qualifica como direito natural. Por outro lado, certos mecanismos utilizados para essa garantia conflitam com outros direitos humanos de caráter individual tão caros quanto.

Como forma de solucionar o conflito ou até mesmo justificar a opção pela prevalência da proteção coletiva em detrimento das garantias individuais de terroristas ou suspeitos de terrorismo, retomou-se a doutrina desenvolvida em 1985 pelo alemão Gunther Jakobs, denominada Direito Penal do Inimigo (Feindstrafrecht), a qual traz o modelo autoritário do direito penal preventivo, por meio do qual são negados direitos humanos e garantias jurídicas do cidadão das pessoas que são consideradas como fonte de perigo extremo em razão de um comportamento suspeito (GALLI, 2011).

Destaca-se que um dos fundamentos da doutrina trazidos por Jakobs (2005) faz uso da concepção contratualista hobbesiana, segundo a qual, não obstante o delinquente mantenha a condição de cidadão, a natureza de certos crimes pode revogar essa condição, caso em que considera o retorno desse indivíduo ao estado de natureza e o mesmo passa a ser tratado como inimigo.

A tendência em considerar que a reação ao terrorismo tem sofrido latente influência do direito penal do inimigo decorre da análise de que, em diferentes ordenamentos jurídicos, as respostas a esse fenômeno consistiram em restrições desproporcionais aos direitos humanos, com ênfase nas liberdades individuais, para punir e perseguir suspeitos de terrorismo, pressupondo inclusive restrições a direitos e garantias de cunho processual (FORTEA, 2011) ${ }^{17}$.

Outra influência da doutrina alemã que será melhor visualizada pelos exemplos trazido no próximo capítulo, refere-se ao fato de que as legislações penais antiterroristas não apenas introduziram novos delitos acerca da prática do terrorismo, seus derivados e lhes aplicando penalidades desproporcionais, mas promoveram uma antecipação da penalização no que tange a análise do iter criminis, passando a considerar como crime certos atos que, pelo direito penal comum, seriam considerados meros atos preparatórios, isto é, aqueles nos quais se verifica estar longe a concretização de algum dano, delineando esboços de uma justiça preventiva (GALLI, 2011).

\section{Reação das legislações nacionais face o terrorismo internacional}

Ante esse novo formato de terrorismo, cujos limites territoriais são ausentes e os instrumentos se alicerçam em tecnologia avançada, o estado de tensão por ele criado exigiu uma resposta dos Estados, a qual vem resultando em alterações de caráter significativo na legislação de uma vasta quantidade de países.

Uma primeira forma de reação adotada e já mencionada anteriormente, recaiu sobre o recurso ao estado de exceção, seja com fundamento nas Constituições nacionais ou em documentos internacionais, como instrumento legitimador da revogação temporária de direitos humanos em prol ao combate do terrorismo e garantia da segurança nacional.

O estado de exceção, de uma forma geral, é utilizado quando presente uma situação que impossibilita o normal funcionamento no aparato constitucional, ou constitui uma ameaça à sua existência, constituindo uma ruptura da normalidade que, nem sempre, pode ser confrontada segundo o regime da normalidade constitucional. Desse modo, os regimes emergenciais geralmente resultam na suspensão da normalidade, com o resultado de alterar o regime de alguns

\footnotetext{
${ }^{17}$ Nesse sentido, Durán (2001) cita as medidas instituídas pelo USA PATRIOT ACT nos Estados Unidos, dentre as quais a Intelligence Reform and Terrorism Prevention Act (IRTPA), que permitia a possibilidade de vigilância no exterior de pessoas envolvidas no terrorismo ou na preparação dos mesmos, mesmo se tais pessoas não fossem apoiadas por Estados estrangeiros (os chamados lone wolf terrorists).
} 
direitos e as competências constitucionais, na medida em que há uma ampliação dos poderes do Executivo, especialmente através dos decretos-lei (VERGOTTINI, 2004).

Nesse sentido, cita-se que o Reino Unido ${ }^{18}$, mesmo após ter internalizado a CEDH por meio do Human Rights $A c t^{19}$, sob o fundamento de se encontrar em situação de emergência face o terrorismo norte-irlandês que ameaçava a vida da nação, alegou no ano de 2001 o artigo 15 da Convenção para justificar a adoção de uma série de medidas derrogatórias dos direitos (DURÁN , 2010).

Assim, foi vislumbrada na Anti-terrorism, Crime and Security Act de 2001, a possibilidade de o Secretário de Estado emitir certificados destinados a pessoas de nacionalidade estrangeira, sobre as quais recaíssem razoáveis crenças de que a presença no Reino Unido consistia em risco à Segurança Nacional ou de que eram suspeitas de terrorismo, possibilitando a deportação desses indivíduos ou a recusa da sua entrada ${ }^{20}$.

Permitiu-se também a prisão administrativa por prazo indeterminado desses indivíduos não apenas no período antecedente à deportação para o seu país de origem, mas inclusive nos casos em que não essa não fosse possível temporária ou indefinidamente, por razões de compromissos jurídicos internacionais do Reino Unido ou por políticas internas (RUIZ, 2010).

Essa lei britânica foi questionada sob o ponto de vista da não-discriminação, considerando que o certificado somente abrangia os indivíduos de nacionalidade estrangeira e, conforme leciona Jiménez Fortea (2011), mesmo que haja razões para a alegação do artigo 15 e a consequente derrogação de certos direitos, essa tem limites, não podendo envolver discriminações por razões exclusivas de raça, cor, sexo, língua, religião ou origem social (FORTEA, 2011).

Nessa seara, em 16/12/2004 a Câmara de Lordes declarou a restrição das medidas a estrangeiros como incompatíveis com a CEDH pelo seu caráter discriminatório, além da prisão por tempo indefinido ter sido considera ilegal (PEÑAS, 2011). Todavia, a lei permaneceu formalmente em vigor até 11/03/2005 quando foi substituída pela Prevention of Terrorism Act, na qual os certificados foram substituídos por ordens de controle (DURÁN, 2010).

Ressalta-se ainda, que a lei antiterrorista britânica de 2001 reconheceu amplos poderes à polícia. Entretanto, esses não se restringiam a luta "contra o terror" e podiam ser estendidos a outros crimes graves, sob o argumento de que os terroristas geralmente se envolvem em crimes não relacionados diretamente com terrorismo e, por consequência, as medidas deviam ter âmbito amplo de aplicação. Desse modo, permitiu-se a possibilidade de proceder a identificação forçosa de detidos que não podiam ou não queriam se identificar, mesmo que o delito não se relacionasse com o terrorismo (RUIZ, 2010).

Também foi aprovada na Índia a Prevention of Terrorism Ordinance n. 09/2001, de 24 de Outubro, pela qual, ao aplicar a previsão de estado de emergência do artigo 123 da Constituição,

\footnotetext{
${ }^{18}$ Cumpre destacar que, conforme Ruiz (2010) no ano de 2000 havia sido publicada uma lei antiterrorista britânica (Terrorism Act) com latente influência da cultura dos direitos humanos introduzida pela Human Rights Act naquele mesmo ano. Todavia, as amplas garantias resguardadas nessa lei foram substituídas por um regime limitativo de direitos na sequência do 11 de Setembro de 2001.

${ }^{19}$ Lei aprovada em 1998 mas que somente teve a totalidade do seu conteúdo recepcionada em 2000. Ressalta-se que a rápida reação do Reino Unido ao terrorismo internacional, considerando que a Anti-terrorism, Crime and Security Act foi promulgada apenas 2 meses após o atentado de 11 de Setembro de 2001, se deve, conforme leciona Ruiz (2010), por se tratar de um Estado que há mais de meio século luta contra o terrorismo norte-irlandês separativista.

${ }^{20}$ Conforme Seção 21 da Anti-terrorism, Crime and Security Act - Reino Unido/2001. Ainda, Peñas (2011) afirma que esse certificado decorria de mera declaração do Home Secretary que entendia ser um indivíduo não britânico suspeito de terrorismo.
} 
possibilitou a derrogação de princípios constitucionais relativos à inviolabilidade pessoal, à proibição de detenções ilegítimas, ao direito de defesa, passou a estar prevista a pena de morte, foram atribuídos amplos poderes de investigação às autoridades e eliminadas as formas de proteção legal dos suspeitos de terrorismo (VERGOTTINI, 2004).

Não obstante uma resposta inicial consolidou-se no recurso ao denominado estado de exceção, em razão da influência da doutrina do direito penal do inimigo e, em especial, em virtude do desenvolvimento da concepção de que o terrorismo implicava em um estado de tensão e não de exceção, houve uma modificação da postura dos Estados quanto à forma de repelir o terrorismo ${ }^{21}$.

Assim, os Estados tendencialmente deixaram de invocar regimes de emergência para justificar a adoção de medidas derrogatórias de direitos e passaram a gestacionar o combate ao terror por meio da legislação nacional infraconstitucional ${ }^{22}$, seja utilizando a ordem jurídica ordinária aplicada à normalidade ou pela previsão de disciplina específica de combate ao terrorismo.

Deve-se sopesar, todavia, que em um estado de tensão, as limitações de direitos geralmente são suscetíveis de atingir maior amplitude do que a declaração do estado de exceção. Tal afirmativa se justifica porque, como esse estado intermediário pressupõe a existência de um perigo difuso cujo dano pode se concretizar em qualquer lugar, geralmente as constituições não limitam o âmbito de direitos que podem ser restringidos para evitar a ocorrência do dano, permitindo, assim, que todos sejam afetados e, além disso, as medidas adotadas tendem a ter sua vigência prolongada (DURÁN, 2010).

Por conseguinte, as respostas atuais ao fenômeno terrorista na Europa Ocidental devem ser analisadas sob o prisma de uma realidade em que a crescente sensação de insegurança aconselha a adoção de uma postura mais severa dos Estados, a qual resulta em uma normalização das medidas combativas e suscetibiliza o aparecimento de um "nós e eles" na justiça penal, oriundo do direito penal do inimigo (GALLI, 2011).

Conforme essa lógica, ao analisar o sistema jurídico italiano diante da ameaça terrorista nacional ou internacional, Vergottini (2004) argumenta que se têm recorrido às fontes previstas na Constituição, lei e decreto-lei. Entretanto, o autor ressalta para o fato de que o recurso à lei, confirmatória dos decretos que introduzem medidas provisórias, tem concedido permanência e continuidade às disposições que foram requeridas com caráter transitório em conexão com a situação de emergência.

Na mesma exegese, retoma-se sob enfoque a legislação britânica, a qual, ao substituir os certificados pelas ordens de controle, superou o vício discriminatório, mas não o relativo à violação de direitos humanos.

Tal assertiva se justifica em virtude dessas ordens, que podem ser derrogatórias ou não derrogatórias, sujeitarem tanto os estrangeiros como cidadãos britânicos. As primeiras têm aplicabilidade quando um indivíduo representa um perigo à segurança nacional em uma situação

\footnotetext{
${ }^{21}$ Vegottini (2004) destaca que a declaração de guerra ao terrorismo realizada pelo presidente estadunidense no ano de 2001, tratou-se de uma exceção que se encontra tendencialmente em desuso. Essa modificação de postura coaduna com a natureza democrática da maioria dos países, tendo em vista que a alegação do Estado de Exceção em resposta ao terrorismo e a consequente permissão de derrogação temporária de direitos, segundo Durán, geralmente evidencia se tratar de um Estado que possua dificuldade em consolidar um sistema democrático e cujo sistema político possui elementos autoritários.

${ }^{22}$ Destaca-se que de acordo com Galli (2011, apud MASFERRER), as medidas específicas de combate ao terrorismo se destinam a abordar uma brecha encontrada no quadro jurídico existente, ou seja, devem ser adotadas quando não for possível trazer soluções por parte do sistema jurídico já existente. Assim, processo criminal ordinário permaneceria sendo a principal resposta a crimes graves, incluíndo o terrorismo, fazendo uso mínimo de medidas administrativas, ou seja, as introduzidas sob o mero critério do executivo.
} 
de emergência, devendo ser emitidas por um juiz e com o prazo de 6 meses, sujeitas, todavia, à renovação. As segundas, por sua vez, são emitidas quando há uma ordem judicial solicitada pelo Secretary of State for the Home Department, cuja revisão desse ser efetuada em 7 dias após sua concessão e possuem o objetivo de proteger a sociedade do risco de terrorismo (VERGOTTINI, 2004).

Essas medidas permitem manter os suspeitos de terrorismo detidos ou ainda restringir seu acesso aos meios de comunicação, sejam eles telefones móveis ou internet. Também pode ser limitado o acesso a certos objetos, os trabalhos a desempenhar, os lugares a residir ou mesmo a frequentar (PEÑAS, 2011).

As ordens de controle britânicas, segundo Galli (2011), decorrem de uma política de justiça preventiva bastante recorrente no combate ao terrorismo, nas quais se busca evitar um possível dano colocado pela ameaça terrorista às custas das garantias normais, em especial, relativas ao processo. A autora afirma ainda que essas medidas se qualificam como punitivas, como um pré-castigo, visto o impacto acumulativo das restrições impostas aos indivíduos sujeitos a essas ordens (GALLI, 2011).

Ao longo das modificações promovidas na legislação antiterrorista britânica, traz-se como destaque no contexto da pré-punição a relativamente recente Counter-Terrorism and Security Act 2015 que introduziu na legislação inglesa, entre outras medidas, a “ordem de exclusão temporária" aos cidadãos britânicos, pela qual o indivíduo fica impedido de retornar ao Reino Unido pelo período de dois anos, desde que preenchidas certas condições, inobstante em caso de emergência essas possam ser concedidas pelo Secretário de Estado mesmo sem permissão pelo judiciário.

Além disso, deve-se notificar o indivíduo sobre a sua ocorrência, mas elas podem ser efetivadas mesmo sem que haja o exercício do direito de defesa e "[...] only the Secretary of State may appeal against a determination of the court" (REINO UNIDO, 2018. Tradução livre: apenas o Secretário de Estado pode recorrer contra a determinação da Corte).

Outra referência em que também é possível visualizar os efeitos da justiça preventiva e da influência da doutrina de Gunther Jakobs (2005), decorre da análise do ordenamento jurídico espanhol que na LeCrim (Lei de Processo Penal), prevê uma variedade de medidas restritivas de direitos e liberdades públicas com cunho punitivo no combate ao terrorismo, dentre as quais, cita-se o artigo 384 pelo qual o mero auto do processo por crime de terrorismo tem o efeito de produzir a suspensão automática dos cargos públicos do suspeito (FORTEA, 2011).

Feitos esses apontamentos a título exemplificativo da realidade que vem se construindo quanto às políticas combativas do fenômeno terrorista, é concludente que essas têm o condão não apenas violador de direitos humanos, mas também o efeito de conformar essa violação por meio da internalização da sua prática como situação comum, como normalidade.

Destaca-se, a título de complementação, que a tendência visualizada nos últimos dois anos na França, face a recorrência de ataques terroristas no país, resultou na declaração do estado de emergência para o combate ao terrorismo, como se extrai da notícia da rádio francesa RFI (2017). Assim, o estado de exceção foi declarado inicialmente a partir de 13/11/2015 e após sucessivas prorrogações, ficou vigente até o início de novembro de 2017, quando foi introduzida uma nova legislação antiterrorista ${ }^{23}$

Faz-se alusão ainda que nesse período em que vigorou o estado de exceção formalmente, foram introduzidas pela Lei de 20 de novembro de 2015 notáveis modificações na Lei nº 55-385

\footnotetext{
${ }^{23}$ Informação disponível em: <https://www1.folha.uol.com.br/mundo/2017/10/1931704-macron-sanciona-leiantiterrorismo-que-substitui-emergencia-na-franca.shtml>. Acesso: 07 ago. 2018.
} 
de 3 de Abril de 1955, que regulamenta o estado de exceção, as quais inclusive tornaram possíveis a prorrogação por período superior aos 12 dias que se permitia pela regulamentação antiga. Ademais, havendo suspeita de que o comportamento de uma pessoa ofereça perigo à segurança ou ordem pública, estas podem ser compelidas a se apresentar, até o limite de 3 vezes ao dia, às autoridades policiais, sendo permitida a sua detenção domiciliar e o impedimento nesse período de contatar outras pessoas se o encontro entre as duas constituir uma possível ameaça à ordem pública (FRANÇA, 2018).

Outro aspecto relaciona-se com o desenvolvimento dos mandados de busca e apreensão que permitem ao Ministério da Administração Interna Francês ordenar buscas independente do horário e sem ter de passar pelas autoridades judiciárias, entre outras medidas amplamente restritivas de direitos (FRANÇA, 2018).

Acerca da nova legislação antiterrorista, Lei n²017-1510, de 30/10/2017, implementada em substituição, em tese, do estado de exceção, deveras são as críticas e preocupações que derivam do seu teor, uma vez que essa nova normativa legalizou e, tratando-se de lei, e não de medida temporária, normalizou a restrição de diversos direitos humanos. Cita-se, por exemplo, a autorização dada pelo Artigo 228-2 ao Ministro do Interior quanto a confinar suspeitos de terrorismo em sua cidade de domicílio, mesmo os que não estejam sendo acusados de terem cometido um determinado crime, bastando que haja sérios motivos para acreditar que sua conduta constitua ameaça particularmente séria à proteção de pessoas (FRANÇA, 2018).

Ressalva-se ainda o fato de que em vários países, conforme matéria publicada pela Anistia Internacional da Espanha, foram realizadas reformas constitucionais e legais, as quais têm proporcionado uma maior facilidade quanto à declaração do estado de exceção e sua prorrogação e, ainda, quanto a concessão de poderes especiais aos serviços de segurança e inteligência, muitas vezes com pouca supervisão judicial ou sem nenhuma supervisão (ESPANHA, 2018).

\section{O processo de normalização das medidas antiterroristas}

É possível constatar, como dado comum no combate ao terrorismo, a adoção de medidas legais que introduzem novos tipos de delitos (referente as variações possíveis quanto a prática do terrorismo), preveem variáveis limitações de direitos, inclusive na esfera processual, e ampliam os poderes de investigação (VERGOTTINI, 2004). Todavia, constata-se também a latente tendência pelos Estados de que essas medidas restritivas sejam introduzidas na ordem legal não mais para serem aplicadas quando presente iminente ameaça terrorista (ou seja, excepcionalmente), mas como parte dessa ordem ordinária, ou seja, são internalizadas com caráter de permanência na legislação nacional.

A tendência em compilar medidas antiterroristas sob o caractere da definitividade decorre de políticas governamentais que, sob o fundamento de que o sistema de justiça penal ordinário não é suficiente para repelir o terrorismo, introduzem nele medidas restritivas de direitos impulsionadas pela necessidade de tranquilizar a opinião pública com a mensagem de que o Estado respondeu de forma decisiva à ameaça terrorista, reforçando, assim, sua autoridade (GALLI, 2011).

Acerca dessa tendência, Galli (2011) desenvolve o conceito de normalização das medidas antiterroristas, que retrata um processo no qual as medidas de caráter emergencial, provocadas por eventos extraordinários, tornam-se institucionalizadas ao longo do tempo como integrantes do sistema jurídico-penal ordinário, mesmo depois que as circunstâncias que as justificaram terem desaparecido (GALLI, 2011). 
Ressalta-se que, apesar de certos governos se comprometerem a introduzir nas leis antiterroristas a sunset clauses, as quais impõem o dever de revisão dessas leis, como ocorreu com a lei antiterrorista britânica de 2001 que continha uma cláusula que impunha a sua revisão anual (PEÑAS, 2011), essas sozinhas não impedem esse processo de normalização ${ }^{24}$.

Conforme analisadas as legislações, a normalização geralmente ocorre inicialmente por sucessivas prorrogações de leis emergenciais, as quais, por fim, acabam adentrando na ordem jurídica de forma definitiva ${ }^{25}$.

Não obstante inicialmente sejam introduzidas as cláusulas de caducidade e a consequente revisão periódica das leis excepcionais de combate ao terrorismo, no plano fático, as medidas antiterroristas adotadas nos últimos 20 anos que, inicialmente tinham caráter transitório, passaram a se planificar definitivamente dentro da legislação (GALLI, 2011).

Outra constatação é que, com o implemento das medidas restritivas de direitos em prol ao combate do terrorismo, verifica-se que as restrições não possuem aplicabilidade prevista apenas aos delitos relacionados com terrorismo. Assim, as legislações acabam por deveras ampliar o âmbito a outros delitos, sob argumentos, como o já mencionado no Reino Unido, de que muitos terroristas cometem outros crimes que nem sempre são conexos ao terrorismo e, desse modo, amplia por consequência o alcance das restrições de direitos humanos.

Desta via, emergem dois questionamentos. Ao analisar a influência de uma doutrina do direito penal do inimigo e a utilização do princípio da precaução como justificativa para adotar políticas de justiça preventiva, não configurariam as medidas dessa lógica decorrentes como pré-punições? Além disso, essas pré-punições, somadas ao processo de normalização de medidas antiterroristas de cunho restritivos e até derrogatório de direitos conjuntamente, não seriam incompatíveis com a concepção de Estado Democrático e Constitucional de Direito e com a própria noção de garantia de direitos nesse âmbito?

\section{Medidas antiterroristas e a (in)compatibilidade com o Estado Democrático e Constitucional de Direito}

Tendo sob perspectiva a construção do constitucionalismo exposta anteriormente, seja em sua acepção endógena e em um momento posterior com objetivo de difusão global, não há dúvidas que o Estado possui sua legitimidade, de uma forma quase generalizada no globo, resguardada pelo processo democrático.

Nesse sentido, afirma Teixeira (2008, p. 234) que desde os movimentos constitucionalistas ocorridos no período moderno "[...] os direitos básicos do ser humano e a forma de governo pautada pela vontade da maioria se apresentam como duas realidades estreitamente interligadas e complementares entre si".

Outrossim, em um verdadeiro Estado Democrático e Constitucional de Direito sustentado por fornecer segurança jurídica (CANOTILHO, 2003) a seus cidadãos, visto ter como bússola o princípio da legalidade, do qual derivam premissas (garantias) tais quais "nullum crimen nulla

${ }^{24}$ É nesse sentido que Walker (2018, p.1423), ao criticar as sucessivas renovações das ordens de controle, afirma "expedients such as control orders may be acceptable in extremis by providing short-term abeyances from criminal justice but should not be adopted as long-term solutions to troublesome friends or foes".

${ }^{25}$ Nessa linha, o site da Anistia Internacional da Espanha publicou uma matéria em janeiro de 2017, alertando que "Las medidas temporales de excepción, como las órdenes administrativas para controlar la circulación de personas en Reino Unido y Francia, se han integrado cada vez más en la legislación ordinária" e sobre o fato destas serem discriminatórias. 
poena sine praevia lege", verifica-se que o direito penal situado sob esse paradigma possui duplo objetivo. O primeiro reside no combate à delinquência por meio da perseguição e, sendo o caso, condenação de suspeitos, mas também se destina a tutelar os direitos individuais dos suspeitos e acusados no âmbito do devido processo (GALLI, 2011).

Assim, considerando a democracia como regime de governo erigido sob a vontade popular e instituído sob os pilares do Estado Constitucional de Direito, não assiste razões e não é atribuído ao Estado a competência de excluir da condição de ser humano como propõe a doutrina do direito penal do inimigo, na medida em que tal lógica contrariaria a própria gênese da democracia, que funciona como condição e garantia dos direitos fundamentais e, em geral, das próprias vertentes de liberdades do homem (ANDRADE, 2016).

Resta assim, como absolutamente condenável qualquer reposta ao terrorismo internacional dentro de uma comunidade política em que seus membros vivam em condições de liberdade e igualdade, na qual se negue a condição de pessoa a uma categoria de indivíduos descritos como inimigos e, por conseguinte, não lhes reconheçam direitos inerentes a essa condição (FORTEA, 2011).

Desse modo, a compilação de leis antiterroristas deve ser guiada pela proporcionalidade, sem influência da punição antecipada oriunda da justiça preventiva e do direito penal do inimigo. Em caso de suspeita de terrorismo, deve ser exigido um standard probatório mínimo para que sejam possíveis as medidas intrusivas em relação ao indivíduo e não como se tem visualizado, a mera suspeita tornar legítima diversas violações a direitos humanos e verdadeiras punições sem prévia condenação (GALLI, 2011).

A grande questão, segundo Jiménez Fortea (2011), reside em estabelecer qual o momento em que está "cruzando la línea" e adentrando em um direito penal e processual do inimigo com as consequências desastrosas que esse proporciona a gama de direitos individuais. Portanto, é necessário que seja estabelecido previamente se essas restrições de direitos e liberdades são cabíveis e a que tipo de direitos (FORTEA, 2011).

O autor alega ainda que, apesar das justificativas das leis restritivas no combate ao terrorismo invocarem que a limitação em matéria de direitos, em geral, são sempre possíveis face essa possibilidade constar em Constituições ou ainda em Convenções Internacionais, essas restrições somente podem produzir efeitos práticos nos limites dispostos por esses mesmos documentos, seguindo seus procedimentos e regras ${ }^{26}$.

É nessa linha que devem ser estabelecidas previsões limitativas ao Estado para que este salvaguarde os direitos humanos, dificultando o exercício de um poder sem restrições justificado em uma suposta soberania nacional e legitimidade democrática.

Assim, impera-se o reconhecimento de alguns direitos humanos que são prévios ao Estado e não meras criaturas do Estado (direitos pré-políticos ou natuais), sobre os quais nenhum ente político pode dispor ou legislar à vontade, de modo que se evite a concepção de que o combate ao terrorismo é um passaporte formal que permite o exercício de um poder excessivo sob a justificativa de garantia da segurança coletiva (MASFERRER, 2011).

\footnotetext{
${ }^{26}$ No mesmo sentido, o Parlamento Europeu em seu Relatório proferido no ano de 2015 sobre a situação dos direitos fundamentais na União Europeia, afirmou sobre ser fundamental a manutenção do equilíbrio entre a proteção das liberdades e dos direitos fundamentais dos cidadãos da UE e o reforço da sua segurança nas políticas de combate ao terrorismo e, ainda, que a necessidade e a proporcionalidade devem ser os princípios preponderantes neste domínio, para evitar que as políticas aplicadas transgridam as liberdades públicas. Relatório Parlamento Europeu sobre a situação dos direitos fundamentais na União Europeia de 16 de Julho de 2015.
} 
Uma medida colaborativa consiste na previsão dos limitativos nas próprias constituições, tendo em vista que quando essa não possui em seu corpo a regulamentação pormenorizada das situações excepcionais, abre-se espaço para as dúvidas interpretativas que legitimam as medidas infraconstitucionais amplamente discricionárias, face as lacunas na Constituição levarem a uma interpretação extensiva (VERGOTTINI, 2004).

Embora a constitucionalização de limites não assegure uma completa resolução do problema, ao menos haveria um parâmetro para um efetivo controle de constitucionalidade, de modo que se exigiria um papel de relevo do judiciário na fiscalização da constitucionalidade das normas antiterroristas.

Trazendo à baila o segundo questionamento concernente ao processo de normalização das medidas antiterroristas, é evidente que este, ao introduzir na ordem ordinária as legislações antiterroristas com caráter restritivo e até derrogatório de direitos humanos, torna normal a violação a esses direitos e, sobretudo, o grande perigo reside no fato de que esse novo regime, que prevê poderes extraordinários como comuns e ordinariamente aplicáveis, passa a ser o padrão para a concepção de políticas futuras (GALLI, 2011).

Nesse sentido, Galli (2011) aduz que as leis antiterroristas restritivas de direitos devem ter em seu bojo as sunset clauses ${ }^{27}$ que garantam que as exceções serão aplicadas por um período limitado de tempo e serão objeto de revisão periódica em relação a necessidade de sua permanência e conforme dito anteriormente, que a revisão também abranja o objectivo e o âmbito específico de aplicação das medidas (GALLI, 2011).

Releva-se que a adoção do Princípio da Proporcionalidade como parâmetro norteador das legislações antiterroristas, negando o tratamento do suspeito como inimigo ou qualquer tipo de pré-punição é indispensável, visto que é precisamente em tempos de crises, segundo Masferrer (2011), que o Estado Democrático deve aderir um caminho que respeite de maneira estrita os seus princípios genuínos, pois os direitos fundamentais perderiam todo o seu efeito se fossem meramente revogáveis em situações críticas ou necessidade. $O$ autor também sustenta que políticas que envolvam a privação das pessoas dos seus direitos e liberdades para manter a segurança colocam o estado no nível dos terroristas, para quem o fim justifica os meios (MASFERRER, 2011).

Desse modo, cita-se o trecho da Proposta do Parlamento Europeu sobre a situação dos direitos fundamentais na União Europeia (Relatório de 16 de Julho de 2015), que dentro do tópico liberdade e segurança, assim determinou no ponto $26^{28}$ :

Observa que os atos de terrorismo criaram uma necessidade urgente de a UE e os Estados-Membros intensificarem as medidas de combate ao terrorismo e à radicalização; insta a UE e as autoridades nacionais a adotarem essas medidas no pleno respeito dos princípios da democracia, do Estado de direito e dos direitos fundamentais, nomeadamente o direito à defesa em processos judiciais, da presunção de inocência, do direito a um processo equitativo e do direito ao respeito da vida privada e da proteção dos dados pessoais; solicita aos EstadosMembros e à Comissão que avaliem, com toda a transparência, a conformidade com o artigo 2. do TUE e a Carta dos Direitos Fundamentais de qualquer

\footnotetext{
${ }^{27}$ Nesse sentido, o próprio Parlamento Europeu no ano de 2003 já advertiu por meio de um informativo sobre a situação dos direitos fundamentais na União Europeia, em relação a importância das legislações antiterroristas preverem cláusulas de revisão. (VERGOTTINI, 2004)

${ }^{28}$ Relatório Parlamento Europeu sobre a situação dos direitos fundamentais na União Europeia de 16 de Julho de 2015.
} 
projeto ou proposta de ato regulamentar e legislativo nacional que se insira no âmbito da luta contra o terrorismo.

Verifica-se assim, tratar de uma falácia a sustentação da lógica de que a restrição dos direitos humanos é uma condição necessária para fortalecer o Estado na luta contra o terrorismo, inclusive porque esta opção levaria inevitavelmente também na falta de segurança dos cidadãos contra o Estado (MASFERRER, 2011) tornando tais medidas incompatíveis com o regime Democrático e a formatação de um Estado Constitucional de Direito.

\section{Considerações Finais}

Não restam dúvidas de que o terrorismo internacional, considerado como um dos novos riscos inerentes ao processo globalizador, constitui evento que exige a adoção de políticas e medidas legais com maior ingerência pelo Estado no exercício de certos direitos fundamentais.

Ocorre que, como foi possível observar, a introdução de medidas de combate em um contexto de estado de tensão (DURÁN, 2010), em virtude da ausência de limites bem delineados, acaba por promover um conflito de difícil solução onde se confrontam garantia da segurança nacional e proteção de direitos humanos, especialmente no que diz respeito à questão clássica dos limites do poder do Estado em face do indivíduo, deixando dúvidas sobre qual seria a melhor alternativa para combater essa emergência balanceada com a garantia de certos direitos.

Conforme analisado, no objetivo de enfrentar o terrorismo, entende-se que o recurso ao estado de exceção não configura como a hipótese mais adequada, tendo em vista que a ameaça terrorista é permanente, incompatível com o funcionamento dos regimes emergenciais que se caracterizam por ameaças de duração determinada ou com estimativa de término ${ }^{29}$. Além disso, nestes são atribuídos maiores poderes ao executivo e retrocede-se ao passado, segundo Vergottini (2004), no qual o governo estava habilitado a decidir sem concurso parlamentar.

Considerando que são as políticas e medidas antiterroristas, seja no âmbito jurídico ou administrativo, as principais fontes de graves violações aos direitos humanos face a influência de doutrinas como a do direito penal do inimigo, interessante solução consiste na adoção pelas Constituições de um tratamento específico do terrorismo, estabelecendo critérios e limites mínimos das medidas e pormenorizando as situações de cabimento ${ }^{30}$.

Uma previsão constitucional que forneça parâmetros de balanceamento e proporcionalidade nas leis de combate ao terror, reduz a possibilidade de restrições de direitos humanos de forma generalizada, isto é, aos casos em que nem haja fundada suspeita de terrorismo, bem como a sua extensão a crimes desconexos com o terrorismo.

\footnotetext{
${ }^{29}$ Nessa exegese, leciona Durán (2010) que reconhecimento de um estado de exceção ou necessidade diante de ameaças terroristas não permite um enquadramento tão simples, tendo em vista ser necessário primeiro definir se tal fenômeno constitui ameaça excepcional ou apenas o causador de um estado intermediário de tensão.

${ }^{30}$ Para a definição de limites, além dos critérios de proporcionalidade, a jurisprudência do TEDH poderia fornecer um norteamento, visto que essa tem fixado inúmeros princípios sobre a suspensão de direitos no combate ao terrorismo, tais quais: somente realizar as suspensões quando se revelem ineficazes os remédios ordinários; assegurar o direito de defesa e os controles jurisdicionais sobre as medidas adotadas, bem como o informe destas aos órgãos da Convenção tornando possível o controle a nível internacional. (VERGOTTINI, 2004).
} 
Assim, a elaboração das legislações antiterroristas não seria desprovida de limites e, portanto, o núcleo essencial dos direitos humanos restaria resguardado ${ }^{31}$. Ademais, após editadas e implementadas na ordem jurídica interna, face as previsões constantes no corpo da Constituição, embora tal medida não sele definitivamente a porta contra possíveis legislações antiterroristas incompatíveis com os direitos humanos, ao menos reforça a fechadura ao reafirmar o papel do poder judiciário quanto à possibilidade da realização de um verdadeiro controle de constitucionalidade.

Pelos motivos já expostos, indispensável também se impõe a rejeição de processos de normalização das medidas antiterroristas (e também da facilitação do estado de emergência, em razão da recente tendência dos Estados em tornar a sua declaração e prorrogação menos rigorosa), através dos quais, tornam-se as restrições e violações de direitos humanos como aplicáveis mesmo em situações de normalidade não mais sujeitas a revisão periódica e, conforme frisado algures, ampliadas essas a crimes nem sempre conexos com o terrorismo.

Deve-se ressaltar para o fato de que o processo de normalização oferece outro perigo além do descrito por Francesa Galli (2011) pois, na medida em que as leis antiterroristas que, em sua gênese, visavam combater uma situação excepcional, vão sucessivamente sendo prorrogadas até definitivamente fazerem parte da ordem jurídica ordinária, isto é, no seio da normalidade, o legislativo gradativamente apaga das memórias sociais a antiga realidade em que um Estado Constitucional e Democrático de Direito de fato garantia direitos e somente os restringia quando presentes situações excepcionais, e sobrepõe sobre essa a naturalidade da restrição de direitos humanos, evidentemente colidentes com a própria legitimidade democrática do poder estatal.

Por fim, considerando o Estado Democrático de Direito como fundamentado na vontade do povo, além da proporcionalidade balancear as medidas a serem adotadas nas políticas antiterroristas, legítimo é que essas passem sob o escrutínio público ${ }^{32}$, visto que serão os seus direitos colocados em cheque diante de conflitos e situações emergenciais.

Embora o conflito decorrente da contraposição entre segurança e direitos humanos pareça ser elementar ao próprio funcionamento do aparato estatal, uma vez não haver direito absoluto, não há que se olvidar a indispensabilidade de que a escolha da sobreposição de um sobre o outro, a depender do caso concreto, seja equilibrada e amparada por critérios de proporcionalidade.

\section{Referências}

ACCIOLY, Hildebrando; SILVA, G. E. do Nascimento e; CASELLA, Paulo Borba. Manual de Direito Internacional Público. 20 ed. São Paulo: Saraiva, 2012.

ANDRADE, José Carlos Vieira de. Os Direitos Fundamentais na Constituição Portuguesa de 1976. 5. ed. Coimbra: Almedina, 2016.

ARENDT, Hannah. Origens do totalitarismo. Tradução Roberto Raposo. São Paulo: Companhia das Letras, 2012.

ARISTÓTELES. Os Pensadores. São Paulo: Nova Cultural, 2000.

\footnotetext{
${ }^{31}$ Nessa linha, Teixeira (2008) afirma que os direitos do homem funcionam como uma imposição de limites às ações políticas nas democracias constitucionais dos Estados modernos e, dessa via, fica a legitimidade da ordem jurídica dependente do respeito a esses limites.

${ }^{32}$ Tal se propõe em virtude dos direitos fundamentais possuírem função democrática, pois o exercício democrático do poder significa a contribuição de todos os cidadãos para o seu exercício bem como implica participação livre assente em importantes garantias para a liberdade de exercício. (CANOTILHO, 2003).
} 
BARROSO, Luís Roberto. Curso de Direito Contemporâneo: os conceitos fundamentais e a construção do novo modelo. 4. ed., São Paulo: Saraiva, 2013.

BARROSO, Luís Roberto. Neoconstitucionalismo e Constitucionalização do Direito (O Triunfo Tardio do Direito Constitucional no Brasil), in A Constitucionalização do Direito: Fundamentos Teóricos e Aplicações Específicas. Rio de Janeiro: Lumen Juris, 2007.

BRASIL. Constituição Brasileira de 1988. Disponível em: <http://www.planalto.gov.br/ccivil_03/ constituicao/constituicao.htm> Acesso: 20 set. 2018.

CANOTILHO, José Joaquim Gomes. Direito Constitucional e Teoria da Constituição. 7. ed. Coimbra: Almedina, 2003.

DURÁN, Manuel Carrasco. Medidas antiterroristas y constitución, tras el 11 de septiembre de 2001. In: DURÁN, Manuel Carrasco (Coord.); ROYO, Javier Pérez (Dir.). Terrorismo, democracia y seguridad, en perspectiva constitucional. Madrid: Marcial Pons, 2010.

ESPANHA. Amnistía Internacional. Publicação: 17 de Janeiro de 2017 Disponível em: <https://www. amnesty.org/es/latest/news/2017/01/eu-orwellian-counter-terrorism-laws-stripping-rights-underguise-of-defending-them/> Acesso 15 ago. 2018.

FRANÇA. État de urgence et autres régimes d'éxception. Disponível em: <http://www.vie-publique.fr/ actualite/faq-citoyens/etat-urgence-regime-exception/\#art12728> Acesso: 07 ago. 2018.

FRANÇA. LOI $n^{\circ}$ 2017-1510 du 30 octobre 2017 renforçant la sécurité intérieure et la lutte contre le terrorisme. Disponível em: <https://www.legifrance.gouv.fr/affichTexte.do;jsessionid=89E348AE1 AB2277B846D56FC894580FD.tplgfr28s_3?cidTexte=JORFTEXT000035932811\&categorieLien=id >. Acesso: 16 ago. 2018.

FERNANDES, Paulo Silva. Globalização, “Sociedade de Risco" e o Futuro do Direito Penal. Coimbra: Almedina, 2001.

FILHO, José Cláudio Monteiro de Brito. Direito Humanos: Algumas questòes recorrentes: em busca de uma classificação jurídica. Direitos Humanos: desafios humanitários contemporânos: 10 anos do Estatuto dos Refugiados (Lei n. 9474 de 22 de Julho de 1997). Belo Horizonte: Del Rey, 2008.

FORTEA, Javier Jiménez. De la restricción de derechos a un «derecho procesal del enemigo». In: MASFERRER, Aniceto (Ed.). Estado de derecho y derechos fundamentales en la lucha contra el terrorismo: una aproximación multidisciplinar (histórica, jurídico-comparada, filosófica y económica). Aranzadi: Pamplona, 2011.

FRANÇA. RFI. Estado de emergência na França é prorrogado até 15 de julho de 2017. Disponível em: < https://www.rfi.fr/br/franca/20161215-estado-de-urgencia-na-franca-foi-prorrogado-ate-15-dejulho-de-2017>. Acesso: 27 set. 2020.

GALLI, Francesca. La legislación antiterrorista en Europa y la normalización de medidas extraordinariais: hacia la prevención, la vigilância y la seguridad. In: MASFERRER, Aniceto (Ed.). Estado de derecho y derechos fundamentales en la lucha contra el terrorismo: una aproximación multidisciplinar (histórica, jurídico-comparada, filosófica y económica). Aranzadi: Pamplona, 2011.

GEARSON, John. The Nature of Modern Terrorism. Superterrorism: policy responses. Oxford: Blackwell, 2002.

HAARSCHER, Guy. A filosofia dos direitos do homem. Tradução de Armando Pereira da Silva. Lisboa: Instituto Piaget, 1997. 
JAKOBS, Gunther. Direito Penal do Cidadão e Direito Penal do Inimigo. In: CAGELARRI, André Luiz; GIACOMOLLI, Nereu José (Org. e Tradução). Direito Penal do Inimigo: noções e críticas. Porto Alegre: Livraria do Advogado, 2005.

MARQUES, Mário Reis - Dos sistemas regionais ao intento global da ONU. Boletim de Ciências Económicas: Homenagem ao Prof. Doutor António José Avelãs Nunes. Coimbra: Separata, 2014.

MARQUES, Mário Reis. A proteção internacional dos direitos humanos. Dos sistemas regionais ao intento global da ONU. Boletim de Ciências Económicas - Homenagem ao Prof. Doutor António José Avelãs Nunes. Coimbra. Separata, 2014, p. 2.006.

MASFERRER, Aniceto. Seguridad y derechos fundamentales em la lucha contral el terrorismo: los limites del poder político en um Estado de Derecho. In: MASFERRER, Aniceto (Ed.). Estado de derecho y derechos fundamentales en la lucha contra el terrorismo: una aproximación multidisciplinar (histórica, jurídico-comparada, filosófica y económica). Pamplona: Aranzadi, 2011.

MONDAINI, Marco. Direitos Humanos. São Paulo: Editora Contexto, 2006.

MUÑOZ, Juan Antonio Martínez. El Derecho ante el terrorismo (el marco hermenêutico básico). In: MASFERRER, Aniceto (Ed.). Estado de derecho y derechos fundamentales en la lucha contra el terrorismo: una aproximación multidisciplinar (histórica, jurídico-comparada, filosófica y económica). Pamplona: Aranzadi, 2011.

PEÑAS, Leandro Martínez. La legislación antiterrorista británica (1990-2010). In: MASFERRER, Aniceto (Ed.). Estado de derecho y derechos fundamentales en la lucha contra el terrorismo: una aproximación multidisciplinar (histórica, jurídico-comparada, filosófica y económica). Aranzadi: Pamplona, 2011.

REINO UNIDO. Counter-Terrorism and Security Act 2015. Disponível em: <http://www.legislation. gov.uk/ukpga/2015/6/part/1/chapter/2/crossheading/imposition-of-temporary-exclusion-orders/ enacted> Acesso: 07 set. 2018.

ROYO, Javier Pérez. Introdução. In: DURÁN, Manuel Carrasco (Coord.); ROYO, Javier Pérez (Dir.). Terrorismo, democracia y seguridad, en perspectiva constitucional. Madrid: Marcial Pons, 2010.

RUIZ, Blanca Rodríguez. Entre la soberanía parlamentaria y los derechos humanos: Seguridad y política antiterrorista en el Reino Unido. In: DURÁN, Manuel Carrasco (Coord.); ROYO, Javier Pérez (Dir.). Terrorismo, democracia y seguridad, en perspectiva constitucional. Madrid: Marcial Pons, 2010.

SILVA, José Afonso da. Curso de Direito Constitucional Positivo. 22. ed. São Paulo: Malheiros, 2003.

TEIXEIRA, António Edílio Magalhães. Proteção dos direitos fundamentais e democracia. Direitos Humanos: desafios humanitários contemporâneos: 10 anos do Estatuto dos refugiados (Lei n. 9474 de 22 de julho de 1997). Belo Horizonte: Del Rey, 2008.

UGATTI, Uendel Domingues. Direitos Humanos em uma leitura histórico/crítica. Direitos Humanos: desafios humanitários contemporâneos: 10 anos do Estatuto dos refugiados (Lei n. 9474 de 22 de julho de 1997). Belo Horizonte: Del Rey, 2008.

UNIÃO EUROPEIA. Relatório do Parlamento Europeu sobre a situação dos direitos fundamentais na União Europeia de 16 de Julho de 2015. Disponível em: <http://www.europarl.europa.eu/sides/ getDoc.do?pubRef=-//EP//TEXT+REPORT+A8-2015-0230+0+DOC+XML+V0//PT\#title1> Acesso: 24 ago. 2018. 
URBANO, Maria Benedita. Curso de Justiça Constitucional, Evolução histórica e modelos de controlo da constitucionalidade. 2. ed. Coimbra: Almedina, 2016.

VERGOTTINI, Giuseppe de. La dificil convivencia entre libertad y seguridad. Respuesta de las democracias al terrorismo. Revista de Derecho Político. n. 61, 2004.

WALKER, Clive. Keeping control of terrorists without losing control of constitutionalism. Stanford Law Review, n. 59, 2007. Disponível em: <https://www.stanfordlawreview.org/print/article/keepingcontrol-of-terrorists-without-losing-control-of-constitutionalism/> Acesso: 04 ago. 2018. 